\title{
Hesio de Albuquerque Cordeiro: além do importante papel como um dos "pais" do SUS, um professor, um reitor, um chefe pra lá de inspirador
}

| ${ }^{1}$ Claudia Leite de Moraes |

${ }^{1}$ Instituto de Medicina Social Hesio Cordeiro, Universidade do Estado do Rio de Janeiro. Rio de Janeiro-RJ, Brasil (clmoraes.uerj@gmail.com). ORCID: 0000-0002-3223-1634

Recebido em: 02/05/2021

Aprovado em: 03/08/2021

Revisado em: 23/08/2021

DOI: http://dx.doi.org/10.1590/S0103-73312021310309

O que escrever sobre Hesio? Difícil dimensionar toda sua importância na saúde pública brasileira. Certamente, outros fariam este resgate de uma forma muito mais rica e competente do que eu. Opto, entáo, por recordar nossos encontros ao longo destes últimos 40 anos, encontros que inspiraram e continuam inspirando muitos de nós.

Conheci Hesio em 1981, quando entrei para a Faculdade de Ciências Médicas da Universidade do Estado do Rio de Janeiro. Logo no primeiro ano do curso, tivemos duas disciplinas no Instituto de Medicina Social ("Fundamentos de Saúde Comunitária" - FUNSACO e "Ciências do Comportamento Humano" - CCH). Se não me falha a memória (lá se vão 40 anos!?), ele compunha o corpo docente de FUNSACO logo em nosso primeiro semestre. Desde então, ele foi um exemplo como médico, professor, pesquisador, gestor, "chefe", colega, amigo e cidadão brasileiro.

Já àquela época, a leitura de seus livros, a atenção às suas aulas e palestras nos mostravam a importância de considerarmos os determinantes sociais no processo saúde-doença e de olharmos o paciente no contexto de sua família, trabalho, comunidade, cultura e meio social. Foi com ele e outros professores do Instituto 
de Medicina Social (IMS) e do Ambulatório de Medicina Integral (AMI), que hoje faz parte do Departamento de Medicina Integral, Familiar e Comunitária (DMIF), que nos fez perceber que nossa missão como médicos seria de promover a saúde, diagnosticar e tratar o doente, e não a doença, e que a saúde não era apenas não estar doente, mas envolvia questôes biopsicossociais. Na época, em meus 17/18 anos, essas ideias eram pra lá de revolucionárias...

A faculdade seguiu seu rumo, cada vez mais "doença" e menos "doente”. Ao longo de todos os seus seis anos, tínhamos no IMS e no AMI nosso porto de resistência a esse modelo médico cada vez mais especializado e tecnicista, e nosso espaço de reflexão sobre a prática, sobre as desigualdades em saúde, sobre a necessidade de um sistema de saúde único e universal que garantisse o acesso à saúde a todos os brasileiros. Cada vez mais envolvida nesse debate, tive a oportunidade de participar do "Internato Rural", uma espécie de "Projeto Rondon" da UERJ, criado em 1984/1985 por Hesio e nosso saudoso João Regazzi, parceiro e fiel escudeiro. Tal iniciativa consistia em proporcionar aos alunos do internato em Medicina um estágio em uma cidade do interior do estado do Rio de Janeiro realizando açôes de promoção de saúde, prevenção de doenças e assistência à saúde, supervisionados por médicos locais e professores da universidade. A proposta visionária de Hesio e Regazzi articulava docência-assistência-pesquisa-extensão e nos mostrava os desafios de uma atuação centrada nas pessoas, suas famílias e seus contextos sociais. Praticamente uma década depois, surgia o "Programa de Saúde da família”, com premissas e práticas muito semelhantes a que desenvolvíamos no Internato Rural.

Nesse mesmo ano (1986), Hesio, então presidente da Associação Brasileira de Saúde Coletiva (ABRASCO), presidiu o $1^{\circ}$ Congresso Brasileiro de Saúde Coletiva, promovido pela Associaçáo, no Rio de Janeiro, que reuniu cerca de 2.500 pessoas das diversas profissões da saúde, provenientes de todos os estados brasileiros, para debater o tema central do evento: Reforma Sanitária e Constituinte, Garantia do Direito Universal à Saúde (REGISTRO, 1986). Sediado na UERJ, o evento contemplou várias mesas-redondas e conferências, comunicaçôes coordenadas e minicursos em torno do tema e muitos trabalhos científicos na sessão de temas livres. Ao final do evento, pactuamos a Declaração Final do Congresso, reafirmando a importância da concepção ampla de saúde trazida pela $8^{a}$ Conferência Nacional de Saúde e conclamando todos ao engajamento na luta pela Reforma Sanitária. Que momento! 
Após breve afastamento da UERJ para minha primeira residência médica em Pediatria, voltei em 1989-1991, como residente da primeira turma de Medicina Geral e Comunitária, na sequência (1991-1993) passei a atuar como médica supervisora de internos e residentes no Ambulatório de Medicina Integral do Hospital Universitário Pedro Ernesto (HUPE). Se não me engano, foi nesta época que entramos de cabeça em sua campanha para a Reitoria da UERJ. Campanha esta que envolveu não só docentes e funcionários técnico-administrativos, mas toda a comunidade discente. Foram incontáveis reuniôes de trabalho, debates da política universitária e políticopartidária, iniciativas para redação e cópia de materiais e eventos para obter recursos para a campanha que sistematicamente terminavam no saudoso botequim Botafogo ou na casa de professores/alunos de diversos setores da universidade, com um violáo e uma cervejinha gelada, fortalecendo a rede de amizade e a certeza de que a universidade deveria ser pública, gratuita e de qualidade.

Salto os anos em que Hesio foi um brilhante reitor da UERJ e alguns anos subsequentes para um tempo mais próximo quando nos reencontramos na Faculdade de Medicina da Universidade Estácio de Sá (UNESA). Ao ser convidado para assumir a Direção da jovem Faculdade de Medicina, em 2002, Hesio, mais uma vez, mostrou seu espírito empreendedor e visionário. Chegou de mansinho e aos poucos foi conhecendo a estrutura curricular, as tímidas parcerias com as unidades do Sistema Único de Saúde, os círculos de gestão e decisão, docentes, alunos e funcionários. Em pouco tempo, como diretor querido e admirado por todos, faz uma reviravolta no projeto pedagógico da faculdade. A partir de debates entre coordenação, professores e alunos, propôs uma reforma curricular que incorporou atividades de integração transversal e longitudinal entre as disciplinas de toda a grade curricular. Criaram-se seminários de discussão de situaçôes de saúde, com a participação de docentes de diferentes formaçóes, oportunidades de pesquisa e projetos de extensão que ultrapassam a formalidade disciplinar.

Nesse cenário de mudanças, em meio à discussão sobre a importância de um Hospital Universitário próprio, Hesio propôs o oposto, ao sugerir que os contratos entre a UNESA e as Secretarias de Saúde fossem ampliados para que os cenários de aprendizagem fossem as unidades de saúde do SUS. Ao invés de práticas clínicas exclusivamente em hospital-escola de alta complexidade, fomos para as unidades básicas de saúde, hospitais de emergência e serviços de ambulatório/ enfermarias do SUS. Em paralelo, ele propôs grupos de trabalho e promoveu 
seminários interprofissionais para a discussão de conteúdos disciplinares visando a uma adaptação da grade curricular às diretrizes curriculares recém-propostas pelo Ministério da Educação para as faculdades de medicina, segundo as quais:

[...] O Curso de Graduação em Medicina tem como perfil do formando egresso/profissional o médico, com formação generalista, humanista, crítica e reflexiva, capacitado a atuar, pautado em princípios éticos, no processo de saúde-doença em seus diferentes níveis de atenção, com ações de promoção, prevenção, recuperação e reabilitação à saúde, na perspectiva da integralidade da assistência, com senso de responsabilidade social e compromisso com a cidadania, como promotor da saúde integral do ser humano. (BRASIL, 2001).

Em uma iniciativa completamente inovadora, os debates culminaram em uma proposta que tinha como eixo formador e estruturante a Estratégia Saúde da Família (ESF) (Programa Saúde da Família à época). A partir de então, disciplinas da ESF foram incorporadas ao rol de praticamente todos os semestres do curso: do M1 ao internato. Foi a oportunidade de formar médicos generalistas, capazes de dar conta das necessidades de saúde das populaçóes adscritas, atuando em rede de referência e contrarreferência com unidades de saúde e apoio diagnóstico de outros níveis do SUS e em redes intersetoriais nos territórios. Corajosa e sem precedentes, a nova proposta curricular previa que a formação médica incorporasse ações de promoção de saúde e prevenção de doenças às que se voltam ao diagnóstico e acompanhamento clínico, entendendo o sujeito/paciente como protagonista do cuidado (BRASIL, 2001). Imaginem o quão difícil foi convencer uma instituição privada a centrar seu currículo nesses conceitos e valores, voltados à formação de um médico generalista que promovesse a atenção integral... Só mesmo o professor Hesio, com seu jeito educado, amigável, manso e ao mesmo tempo firme. E ele não parou por aí...

Sempre com novas ideias, após implantar uma unidade de Saúde da Família na sede da Faculdade de Medicina, na Rua do Riachuelo, que mais tarde passou a compor o conjunto de unidades de saúde da Secretaria Municipal de Saúde e Defesa Civil do Rio de Janeiro, em 2003, Hesio reuniu alguns professores doutores para discutir a possibilidade de abertura de um programa de pós-graduação stricto sensu em Saúde da Família. Considerando o contexto da área de Saúde Coletiva na CAPES, optamos por um curso de mestrado profissional. Seria a oportunidade de qualificar profissionais que já estivessem trabalhando na ESF, seja nas equipes da ponta, seja na gestão. Lembro-me de nossas reuniões para a elaboração da proposta do programa, sob sua genial batuta. Em praticamente três semanas, elaboramos a proposta, grade 
curricular, regimento, definimos as linhas de pesquisa e outros materiais necessários. Em paralelo, sob sua coordenação, fizemos um mutirão visando à construção coletiva do nosso primeiro projeto de pesquisa em parceria com o IMS/UERJ, a ser submetido ao Edital Universal do CNPq. Passamos o final de semana em reuniōes para montar um projeto guarda-chuva que pudesse acolher nossos futuros alunos em subprojetos de pesquisa que se debruçassem sobre problemas relevantes. Não é que deu certo?! Tanto o projeto do curso, como o projeto de pesquisa foram aprovados pela CAPES e CNPq, respectivamente. E assim, em 2004/2005, iniciamos nossas atividades no primeiro Mestrado em Saúde da Família do Brasil.

Como coordenador do programa em toda a sua primeira década, Hesio liderava as atividades acadêmicas e era o mediador dos nossos interesses junto à instituição. Como membro do corpo docente permanente, atuou em todas as disciplinas, orientou um número grande de alunos, participou de todas as reunióes de colegiado, dos seminários de avaliação e de todas as demais atividades do programa. Sempre o primeiro a chegar e o último a sair. Apesar de sempre tentarmos dispensá-lo das atividades do final de semana, ele sempre esteve presente. Não discutia conosco e de repente aparecia lá no horário da aula para a alegria de todos os alunos e professores. Não há um aluno que não tenha uma boa história com ele e que não o reverencie por seu jeito amigo, sua trajetória e competência. Também não poderia deixar de enfatizar a importância de Hesio dentre os docentes do programa. Todos sentimos e continuamos a senti-lo como nosso professor, guru, coordenador, amigo e maior inspiração. Com sua sabedoria própria, agregava quem viesse para a discussão. Em todas as polêmicas de nossa equipe, das mais simples às mais cabeludas, ele nos ouvia com atenção, quieto, deixando-nos expor os argumentos, as inquietaçóes, as sugestóes nem sempre consensuais para, ao final, de mansinho, fazer uma proposta conciliadora, acolhedora dos pontos de vista divergentes e quase sempre genial. Ao falar do Hesio, sempre digo que ele foi o melhor "chefe" que já tive: doce, respeitoso, acolhedor, instigador, vibrante e corajoso. Sempre vendo no futuro uma oportunidade de "arregaçar as mangas" em projetos em defesa da vida e do SUS.

Por fim, náo poderia deixar de trazer para este texto sua generosidade em compartilhar conosco sua casa, sua família, seus amigos em aniversários, comemoraçóes e eventos em geral. Sempre nos acolhendo e nos deixando absolutamente à vontade, apesar de estarmos diante do nosso maior exemplo na luta pela saúde da população brasileira. Seja em suas feijoadas de aniversário, seja na 
casa de algum de nós, nos almoços em botequins da Lapa ou nos chopes e encontros de final de ano, sempre com uma boa conversa, querendo saber de todos, como estávamos, quais os próximos desafios.

Tudo que escrevi nas linhas acima são só algumas lembranças de alguém muito maior. De coração, me sinto muito honrada e grata por sua companhia desde os meus primeiros dias da medicina até os seus últimos dias, e por trabalhar no Instituto que ele ajudou a criar e que com ele foi decisivo na construção da Reforma Sanitária Brasileira e do SUS.

\section{Referências}

BRASIL. Ministério da Educação. Conselho Nacional de Educação. Câmara de Educação Superior. Resolução CNE/CES n ${ }^{\circ}$, de 7 de novembro de 2001. Diretrizes Curriculares Nacionais do Curso de Graduação em Medicina. Brasília, 2001.

REGISTRO. $1^{\circ}$ Congresso Brasileiro de Saúde Coletiva. Cad. Saúde Pública, Rio de Janeiro, v. 2, n. 3, p. 382-384, set. 1986. https://doi.org/10.1590/S0102-311X1986000300013. 